\title{
(In)compatibility of CLIL and ESP courses at university
}

\author{
Joseba M. González Ardeo \\ fipgoari@Ig.ehu.es \\ Universidad del País Vasco / Euskal Herriko Unibertsitatea, Spain
}

\begin{abstract}
This paper deals with the current coexistence of ESP (English for Specific Purposes) and CLIL (Content and Language Integrated Learning) courses in tertiary educational settings in the Basque Country. The University of the Basque Country (UBC) is immersed in an ongoing process of internationalization and, consequently, its language teachers are witnessing an unstoppable process of Anglicization. At present, and presumably in the medium and long term, institutional decisions will continue to support CLIL in preference to ESP. In order to analyse this process within the UBC, quantitative data about these two linguistic approaches are gathered and compared with data from 2005. A questionnaire aimed at gathering the opinions of engineering students who currently take both types of courses is also used as a source of qualitative data. The main conclusion of this exploratory study is that both types of courses seem to be compatible. However, language teachers, English-medium content teachers and students are facing a tough challenge, since neither of the two types of course is a panacea.
\end{abstract}

Keywords: CLIL, ESP, internationalization of higher education, Anglicization, University of the Basque Country, questionnaire

\section{INTRODUCTION}

In a globalized, postmodern world a rather different model of education has emerged. With the aim of setting up a European Higher Education Area (EHEA), more than forty countries have joined the Bologna Process with the aim of standardizing higher education in Europe and thus make an open market for European and non-European citizens (Wächter 2008). One of the undeniable consequences is the fact that many universities in Europe are desperately trying to internationalize their curricula. This approach offers several benefits, the most obvious of which is that it encourages academic cooperation and, consequently, staff and student mobility.

Internationalization of tertiary institutions usually means implementing higher education in English or, in simpler terms, Anglicization, since universities tend to use this language more and more as a means of instruction and a working language, with the aim of attracting not only international students but also staff and courses. Anglicization 
in higher education means making use of the English language as a lingua franca for academia (Mauranen and Ranta 2009) and converting material in the local language into English in an attempt to increase international cooperation or, more succinctly and directly, introducing a number of English-medium programmes.

The word internationalization primarily suggests, or should suggest, multiculturalism and multilingualism but a flow of cultures and languages other than English does not seem to exist. It is true that languages such as German and French try to keep up with English, but they are significantly less successful. Publication in international journals is a synonym of publication in English. Local languages used for publishing in local publications have little (if any) weight in a globalized world in contrast with almighty English. In fact, most 'international' journals based in non-English-speaking countries have become English-only publications, thus reducing multilingualism in that particular field and eliminating the status of any other language as an international language of science (Hamel 2007). Undergraduate and postgraduate programmes taught entirely in English increase year in, year out (Costa and Coleman 2010, Wächter and Maiworm 2008) not only in Northern Europe, Germany and the Netherlands but also, although at a slower rate, in Southern Europe. Scholars for whom English is their second, or additional, language have a clear disadvantage, since nowadays (on the horns of a dilemma: publish or perish) a teacher may remain unknown on the international stage or academic community if s/he does not publish in English.

At least three main conclusions can be reached from the information presented so far. First of all, as Phillipson (2009: 37) stated, "what emerges unambiguously is that in the Bologna Process, internationalization means English-medium higher education”. Secondly, as Coleman (2006: 11) stated, "it seems inevitable that English, in some form, will definitely become the language of education”. The European shift towards English-medium instruction (Hughes 2008) is one of the consequences of the Bologna Process and it has been a non-stop process since English became the international language for the dissemination of knowledge in, for example, scientific conferences several years ago (Ammon 1996). Finally, it seems to be true that, to a certain extent, most of us are somewhat forced to accept certain, sometimes controversial, beliefs due to the uncritical adoption of Anglo-Saxon paradigms (Phillipson 2006). 
The policies of the Bologna Process state that all university students will have to accredit the knowledge of a foreign language - in the majority of cases English - to B1 or B2 level of the European Framework of Reference in order to obtain their certificates. Therefore, universities will have to provide for this requirement.

This section depicts a scenario in which the term internationalization is a synonym of Anglicization. The following section deals with the role of CLIL (Content and Language Integrated Learning) and ESP (English for Specific Purposes) in this unstoppable process and the way they fight their way through future hegemony.

\section{CLIL VS ESP AND THE ANGLICIZATION PROCESS}

To start with, the theoretical foundations of CLIL must be clearly established (DaltonPuffer 2008). CLIL, a predominantly European movement, is in fact an umbrella term used to describe a whole spectrum of approaches. In other words, it embraces any type of programme where a second language is used to teach non-linguistic content-matter (García 2009, Khoury and Berilgen-Duzgun 2008, Marsh 2002). It consists in learning subject-matter content through the medium of a foreign language, and learning a foreign language by studying subject-matter content. In the CLIL methodology, language is a tool for learning and communicating, and the content determines the language to be learnt. In addition, some researchers (Lasagabaster and Sierra 2010, Navés and Victori 2010) have also pointed out and emphasized the need to have empirical studies that back up statements so often made about the benefits of CLIL, as well as to generalize the implementation of CLIL as a successful teaching model in order to consolidate CLIL programmes. To learn to be effective, it is necessary to integrate receptive and productive skills. Moreover, reading and listening are re-dimensioned, language is functional, lexicon is of paramount importance and the approach is task-oriented.

In 2006, a macro-survey on Europeans' languages was conducted by the European Commission and some alarming (but fairly predictable) conclusions were reached. Spain appears as "the bottom rung of the foreign-language knowledge ladder" (Lasagabaster and Sierra 2009: 7). CLIL has been embraced since then as a linguistic lifebelt or a possible lever for change and success. Consequently, “...the CLIL approach has become an important tool in supporting the achievement of the European 
Commission's objective of improving the foreign language proficiency of its citizens” (Lasagabaster and Sierra 2009: 15). Powered by the aforementioned circumstances, CLIL has had an almost exponential uptake across Europe over the past two decades, gradually becoming an established teaching approach (Järvinen 2007). Teaching through one single language is seen as second rate education (Lorenzo 2007), and thus CLIL is spreading fast. However, the impact of this rapid spread has not been thoroughly researched yet, especially in Spain (Lasagabaster and Ruiz de Zarobe 2010, Ruiz de Zarobe and Jiménez Catalán 2009).

There is also a need to explore how the key concepts of content, language and language learning merge into CLIL (Fernández 2009). The differences between CLIL and other approaches and methodologies developed within the framework of Content-Based Instruction (CBI), e.g. Content-Based Learning (CBL), ESP, Cognitive Academic Language Learning Activities (CALLA), Integration of Content and Language (ICL), Language Across the Curriculum and even Task-Based Learning (TBL), are basically ontological and, consequentially, epistemological. These approaches get bundled together because they share some assumptions, namely: teaching/learning a foreign language is an educational practice; content is inseparable from linguistic expression; it is necessary to coordinate the learning of language and subject-matter; language is the major medium of instruction and learning; subject-matter content contextualizes language learning.

For learning a subject in an L2, learners need three kinds of language and learning skills: basic L2 skills, academic L2 skills, and metacognitive skills. This means that they will have to be able to listen, speak, read and write on a wide range of topics, making appropriate and accurate use of the language at the level of sounds/spelling, grammar, vocabulary, function, and discourse. To learn all this, they take foreign language lessons and L2-medium subject lessons informally outside school. However, learners of subjects in an L2 have to do things with the language which conventional foreign language learners do not have to do. They need what Cummins (1979) calls CALP (cognitive academic language proficiency), a formal, de-contextualized variety of language used in school. These CALP skills are: 1) Listening. Students may have to deal with excellent teacher presentations (well-organized, supported by visuals, etc.), or just the opposite. Moreover, they will have to listen to their peers and try to grasp an 
argument in the broken language typically found in these situations. 2) Reading. Learners will have to read handouts, board work, subject textbooks, and so on, sometimes with the help of diagrams, charts, etc. but sometimes with dense paragraphs in formal language in which sentences are long and complex. Sometimes they will search for information in reference books, the internet, and so on, and will need the necessary skills for using tables, skimming, scanning, etc. They will also have to distinguish central from peripheral information. 3) Writing. Students will have to plan, draft and revise texts by constructing formal sentences accurately, using specific vocabulary, and organizing the sentences in paragraphs. 4) Talking. This will include responding to teacher elicitations, talking in groups (this skill is complex and many students have difficulties even in their L1), making and supporting points, agreeing and disagreeing with others' points, making presentations, and so forth, sometimes using various visual means of conveying data. 5) Functions. Thinking skills such as defining, classifying, hypothesizing, comparing, expressing cause and effect, time sequence, and so on, are needed. 6) Vocabulary. They will have to learn low-frequency, high-precision subject-specific words and also academic vocabulary or school-specific words and phrases for expressing, for example, notions of structure, function, type, place, and so forth. 7) Metacognitive skills. Learners need to ask teachers to explain and repeat, to look up words, to remember key phrases useful in academic discourse, to listen carefully for organizational signals in teacher talk, to pre-read texts, etc. These skills will help learners to work efficiently in CLIL lessons, provided of course they are previously or simultaneously trained.

CLIL programmes are considered to be content-based programmes as well as subject programmes. To be sure that students are indeed learning the language, CLIL teachers will have to analyse the language demands of lessons and provide language support to help learners meet them, otherwise learners will learn the subject inefficiently and the language more slowly. Continued development occurs only if subject teachers promote it by drawing learners' conscious attention to language. In other words, for CLIL teachers to be good, they need some skill in language development.

A careful analysis of the development of ESP, on the other hand, brings together key concepts such as register analysis, rhetorical/discourse analysis, situational analysis, skills and strategies, needs analysis, learning-centred processes (Hutchinson and Waters 
1987) and authenticity of input and purpose, which seem to characterize all academic proposals in the field. ESP is designed to meet specific needs; it is related in content to particular disciplines, occupations and activities; it is centred on language (syntax, lexis, discourse, semantics) that is appropriate to the activities; it is non-General English oriented and it has no pre-ordained methodology (discipline, strategy or needdependent) (Bell 2006, Dudley-Evans and St John 1998). In fact, the ESP teacher "should not become a teacher of subject matter, but rather an interested student of the subject matter” (Micic 2005: 5). They should also regard themselves and their students as “professionals who learn and complement each other” (Irizar and Chiappy 2008: 13). Knowledge of the subject and its terminology is important, but it is also important to remember that it is usage of the English language in a specific context which is being taught in ESP, since the focus is on the terminology used in specific fields such as law, medicine, engineering, finance, etc. Consequently, CLIL is not an evolution of ESP because the focus is very different and even if both aim at the same goal of becoming fluent in a language, CLIL does not focus on teaching this language, as opposed to ESP. CLIL and ESP share a number of key features, such as the use of content from different non-linguistic subjects, development of academic and communication skills, and use of communicative language teaching methodology. However, there are some key differences in these two approaches, and one of them is the objectives and learning outcomes. CLIL clearly states that content-learning objectives are equally or even more important than language-learning objectives, whereas ESP is language-led and language-learning objectives are of primary importance.

Another key aspect that both approaches share is the language (L2), but it is approached in a completely different way. In ESP, language is both the content of the course and the means of learning content, it is often adapted to the learners' proficiency level or rather the learners are often grouped according to their levels of language proficiency. In CLIL, it is advised to use 'scaffolding' strategies to make content more manageable without really adapting it (Hammond and Gibbons 2005). In CLIL, language is viewed as a means and not a goal in itself, which means it is learned when needed and not, as in more traditional approaches, ESP among them, when language content leads towards 
the choice of content topics. In CLIL, learning strategies are employed to provide language support for content acquisition.

More tolerance to language usage, more support for language production, enabling learners to acquire language in such a way is one of the key principles of CLIL, as opposed to traditional language teaching. CLIL also tolerates more use of L1, and codeswitching strategies.

One more key difference is the teachers. An ideal CLIL teacher is a subject specialist with an appropriate level of language proficiency. Sometimes in CLIL, tandem teaching by content and subject specialists is used. A typical ESP teacher is a language teacher who does not take on the responsibility for teaching subject content as it is beyond their competence because of the high cognitive demands of the subjects taught in higher education. One of the ways of solving the 'content' issue for the language specialists in higher education is to rely more on project or problem-based teaching and to co-operate with subject specialists.

After analysing the global view of CLIL and ESP methodologies and their current support, the following section focuses on a local scenario: the Basque Country and the use of English at its University.

\section{ENGLISH IN THE BASQUE COUNTRY AND AT THE UNIVERSITY OF THE BASQUE COUNTRY}

The Basque Country (Euskal Herria) is a small stateless nation (20,664 $\mathrm{km}^{2}$ ) located in the vertex of the Atlantic Arc on both sides of the Pyrenees mountain range, divided between Spain and France. Euskal Herria is made up of seven historical territories or provinces. Within the Spanish State: Araba, Bizkaia, Gipuzkoa or the so-called Basque Autonomous Community (BAC) $\left(7,233 \mathrm{~km}^{2}\right)$, and the Charter Community of Navarre $\left(10,392 \mathrm{~km}^{2}\right)$. In the French State, Iparralde (Northern Basque Country) (3,039 $\left.\mathrm{km}^{2}\right)$ is made up of Lapurdi, Behe Nafarroa and Zuberoa. These are part of the département of the Pyrénées-Atlantiques (they do not constitute a single, separate administration in France, despite continual demands for the creation of a Basque département). This division largely explains the different situation presented by each of the three Basque political-administrative units, with respect to both bilingualism and Basque identity. 
The BAC, the most dynamic in the Basque language and culture normalization process, experienced high rates of immigration from other Spanish regions, most significantly at the beginning of the 20th century and during the Franco regime. In terms of population, Euskal Herria has, roughly speaking, 2.9 million inhabitants: 2.1 in the BAC, 0.55 in Navarre and 0.26 in Iparralde. So, the region we are dealing with is a highly complex one.

Only two decades ago, bilingualism in the BAC was the cornerstone of research when Basque versus Spanish competence was evaluated. A gradual shift towards multilingualism is taking place and it is becoming a social phenomenon (governed by the needs of globalization and cultural openness). Multilingual education in the Basque Country reinforced the teaching of English as a foreign language in the curriculum. Foreign-language teaching (English in most cases) is compulsory from the third year of primary school (eight-year-olds), but early instruction in English from the age of four or six is very common. Specific projects to develop trilingual education in Basque schools were developed in the 1990s and they can be regarded as an extension of the bilingual educational system. These projects aim at achieving communicative competence in the three languages (Basque, Spanish and English) and also consider the importance of developing positive attitudes towards the languages. Research carried out in the Basque Country in connection with the level of competence in the three languages has covered a wide range of options. For example, Cenoz and Gorter (2011) analysed the development of writing skills in Basque, Spanish and English; Elorza and Muñoa (2008) focused on how to promote the minority language (Basque) through integrated multilingual language planning; Gallardo del Puerto (2007) analysed L3 (English) phonological competence in connection with the learner's level of bilingualism (Basque/Spanish).

The growth of tertiary CLIL is an institutional initiative dictated by the strategic need for internationalization, one which will enhance the employability of home students while attracting international students (Wächter 2004) in a globalizing academia (Wilkinson and Zegers 2008). Research carried out in the Basque Country confirms that secondary school students enrolled in CLIL classes hold significantly more positive attitudes towards English as a foreign language to teach content than those in EFL classes (Lasagabaster and Sierra 2009), but it is widely recognized that there is a strong 
need for research and better practices in tertiary CLIL settings (Costa and Coleman, 2010, Dalton-Puffer and Smit 2007).

In 2005 the University of the Basque Country (UBC) launched a Multilingualism Plan (to implement an official strategy of the Basque Government) with the general aim of fostering the presence of foreign languages in its curricula. More specifically, these aims can be summarized as follows:

- To provide continuity to the multilingualism projects in which English or French are taught at Secondary School in the BAC.

- To develop linguistic training for students with the aim of facilitating mobility within the EHEA.

- To foster conferences, symposia and other university activities in foreign languages. The plan expects to linguistically qualify students so that they can take more advantage of visiting professors and foreign journals.

- To facilitate the insertion of students on the labour market, since mastering a foreign language has become market value added.

- To widen the options for foreign students in exchange and international programmes. The delivery of lectures in foreign languages is undoubtedly appealing when it comes to attracting foreign students.

- To promote the internationalization of teaching staff, with a view to enhancing their teaching and research careers.

The Plan also states that it will allow students from the UBC to learn not only English and French but also the specific language of each branch or specialization. Taking into account the topic of this paper, the word 'specific' is fundamental in this declaration of principles or intentions.

Nothing at all is mentioned in terms of, for example, teacher training. Consequently, as Wächter and Maiworm (2008) stated, students are exposed to academic staff with a broad range of knowledge from different sources. It therefore seems that CLIL at the tertiary level is often performed in a rather casual manner because university lecturers are not usually inclined to receive training on how to teach in a foreign language. They are content to teach independently, and see no need to discuss issues with language teachers (more specifically, ESP teachers). Even worse, some content teachers may also 
feel that the subjects taught through English will be watered down and simplified in order to make them comprehensible to the students, but in some cases this may be a fallacious argument. In order to justify our statement, let us consider the following summarized version of this UBC agreement - Regulations on how to obtain accreditation for teaching in non-official languages (June 2010): 1) The accreditation certifies that the teacher can teach in the non-official language; 2) The accreditation can be obtained through one of the following ways: a) Through a test that includes two parts. On the one hand there is a written part, in which firstly candidates will have to offer proof of their command of the language in a general way and, secondly, they will have to write a 250-300-word text to prove they have enough ability to write in a clear and comprehensible way about a university topic selected by the candidate from among those suggested by a committee. On the other hand, the test also includes an oral part in which the candidate will have to prove sufficient command of the language to develop and present a university topic chosen from among those suggested by the committee, a task that will last 15 minutes (maximum). b) Through proper accreditation: C1 or higher certificate (CAE is mentioned as an example); merits such as a university degree studied in that language; a $\mathrm{PhD}$ completed in that language; an aptitude certificate granted by Spanish Official Language Schools; having taught at a foreign university in that language for at least 100 hours; other merits.

One conclusion that can be drawn from this scenario is that watered-down versions of CLIL courses may be rather likely in the UBC, due mainly to a prospective lack of professional competence, from a linguistic point of view, of some CLILers. On their part, ESP teachers see a need for collaboration in order to properly define how to teach in English at the tertiary level.

In the following section, current figures of CLIL at the UBC are presented and compared with current figures of ESP. Those figures are also compared with figures from 2005. This will show us the picture of a growing trend in favour of CLIL. Next, an exploratory study is described and its results are presented. The main aim of this study is to quantify to what extent ESP and CLIL courses are (in)compatible at the UBC and, more precisely, how engineering students face the dilemma of choosing CLIL vs. ESP courses (or both) and why they do so. 


\section{CLIL AND ENGINEERING AT THE UNIVERSITY OF THE BASQUE COUNTRY}

As regards the implementation and results of CLIL programmes in the Basque Country, Lasagabaster's study (2008), which compared the linguistic competence of secondaryschool students in CLIL programmes and students in traditional EFL courses, found statistically significant differences in all language skills (including speaking, writing, grammar, listening and overall English competence) in favour of CLIL students in secondary education. Likewise, Ruiz de Zarobe's research (2007) on the oral proficiency of secondary-school learners showed that CLIL learners outperformed nonCLIL learners in most of the measures used to analyse oral skills.

Those in favour of the CLIL approach justify its use by stating that as in secondary education, CLIL-type teaching in higher education increases learner motivation, contributing to both cognitively more demanding content and language learning and communicative skills development. They also state that CLIL enables learners to perform to the level of their linguistic and academic competence. Integrating communication learning outcomes promotes students' ability to observe, adopt and adjust the discursive identity of their discipline (Fortanet-Gómez and Räisänen 2008).

Due to political, economic, academic and cultural reasons, CLIL is undoubtedly gaining ground in the academic market in general, and the BAC is no exception. The recent evolution of CLIL and ESP in tertiary settings within the BAC seems to predict that ESP will be soon fading away with the advent of CLIL.

Table 1 shows the evolution of ESP and CLIL in quantitative terms, that is, by considering 'southern-Europe traditional' credits (10 teaching hours per credit) in 2005, and the ECTS (European Credit Transfer System) credits at present assigned to ESP courses and to CLIL courses. There were no CLIL courses in 2005, but at present the situation has changed radically (and dramatically for those ESP practitioners that have been working in the BAC for the last 30 years). 
Table 1. ESP credits and CLIL ECTS credits in engineering.

\begin{tabular}{|c|c|c|}
\hline & $\begin{array}{c}\text { ESP / CLIL } \\
2005\end{array}$ & $\begin{array}{c}\text { ESP / CLIL } \\
\text { at present }\end{array}$ \\
\hline \multicolumn{3}{|l|}{ Public institutions (UBC) } \\
\hline Faculty of Engineering (BI) & $24 / 0$ & $0 / 82$ \\
\hline School of Technical Industrial Engineering (BI) & $36 / 0$ & $12 / 21$ \\
\hline School of Technical Mining and Public Works (BI) & $12 / 0$ & $0 / 6$ \\
\hline Polytechnic School (GI) & $30 / 0$ & $12 / 12$ \\
\hline School of Technical Industrial Engineering (GI) & $24 / 0$ & $7.5 / 12$ \\
\hline School of Engineering (AR) & $30 / 0$ & $7.5 / 18$ \\
\hline \multicolumn{3}{|l|}{ Private institutions } \\
\hline University of Deusto (BI) & $9 / 0$ & $0 / 42$ \\
\hline Mondragon University (GI) & $18 / 0$ & $3 / 24$ \\
\hline \multicolumn{3}{|c|}{ BAC: BI (Bizkaia), GI (Gipuzkoa), AR (Araba) } \\
\hline
\end{tabular}

\section{EXPLORATORY STUDY}

With the aim of helping to clarify the reality of this new scenario and thus supplement the figures from Table 1, an additional study was carried out to gather information from engineering students about their ESP and CLIL lessons. Their opinions and reasons for choosing both types of courses throw light on the topic and may help us to predict shortterm trends, since both approaches will be compatible only if a synergic phenomenon takes place.

\section{V.1. Sample}

The study was conducted in Bilbao, internationally probably the best known city in the Basque Country. The participants were engineering students from the UBC, to be more precise, from the School of Technical Industrial Engineering. More specifically, they were 23 undergraduates in their last year of study (men/women: 10/13) from different branches of engineering, and their ages ranged from 21 to 26.

\section{V.2. Instruments}

The questionnaire that students were invited to complete (a sample is included as an Appendix) is an original questionnaire in the sense that it is not an adaptation of other 
researchers' questionnaires. The reason for this lies in the peculiar characteristics of the sample used, i.e. engineering students located in the BAC, where Basque (a minority language) and Spanish (an international language) are co-official languages, and where English is extensively used by engineers.

The questionnaire was checked and tested thoroughly prior to being used. Other ESP teachers filtered out unclear or biased items from the questionnaire, and it was tested in a control group before adopting its final version - divided into three separate blocks. The first block gathers information about the students' age and gender. The second one contains 16 statements. The first five items were included in order to gain an idea of the students' attitudes towards English in general, in terms of liking or disliking it and in terms of weighing up its importance for them and for others in the Basque Country. Previous research shows that monolingual (mother tongue: Basque or Spanish) and bilingual (Basque/Spanish) engineering students show overall positive attitudes towards English (González Ardeo 2003). The remaining eleven items were all connected with ESP and CLIL and they attempted to find out whether, in these students' opinion, ESP lessons are more interesting/useful than CLIL lessons or not, and if they think they are compatible despite the sometimes considerable overlap between the subjects. The validity of the questionnaire rests on the fact that these adult students understood clearly enough the role of both CLIL and ESP courses and their differences as well as their similarities. Apart from the fact that the students were directly involved in these courses, they received intensive information about these two topics, and answers were provided to solve all the questions raised in the most effective and complete way. Moreover, in order to reinforce its validity, it can be stated that the questionnaire measures what it was intended to measure, since the questions were phrased appropriately, and the options for responding were also considered appropriate after the sifting process mentioned above. Finally, the last block includes a single statement to somehow filter the answers from the second block and thus try to minimize biased results. This statement ("I would have provided the same answers in this questionnaire if the interviewer had been a CLIL teacher”) expects the students to be as objective as possible - no matter who the interviewer is (ESP teacher versus CLIL teacher). 


\section{V.3. Procedure}

The paper-and-pencil questionnaires were completed in class and the time allowed was 10 minutes. They were printed in English and the answers were recorded on answer sheets, which were evaluated statistically after having been codified.

\section{V.4. Results}

Results were first tabulated. Arithmetical means and standard deviations give us first an overall view of the students' perceptions about the items included in the questionnaire. The standard deviation (SD $=\sigma$ ) has been chosen instead of the average absolute deviation because the former is algebraically simpler though practically less robust than the latter. Moreover, $\sigma$ is commonly used to measure confidence in statistical conclusions.

The distribution of data is normal (bell-shaped), so we will assume that:

$$
\begin{aligned}
& \text { mean } \pm 2 \sigma=95 \% \text { of the population } \\
& \text { mean } \pm 3 \sigma=99.7 \% \text { of the population }
\end{aligned}
$$

Figure 1 shows a summary of the results obtained in terms of descriptive statistics. It can be observed in items 1 to 5 that the dominant attitude towards English continues to be favourable or very favourable, and a strong instrumental but also integrative motivation (Gardner and Lambert 1972) is clear. However, in item 2, "English should be taught to all pupils in the Basque Country”, the scores are comparatively lower (although dispersion is relatively high) and this may deserve additional research.

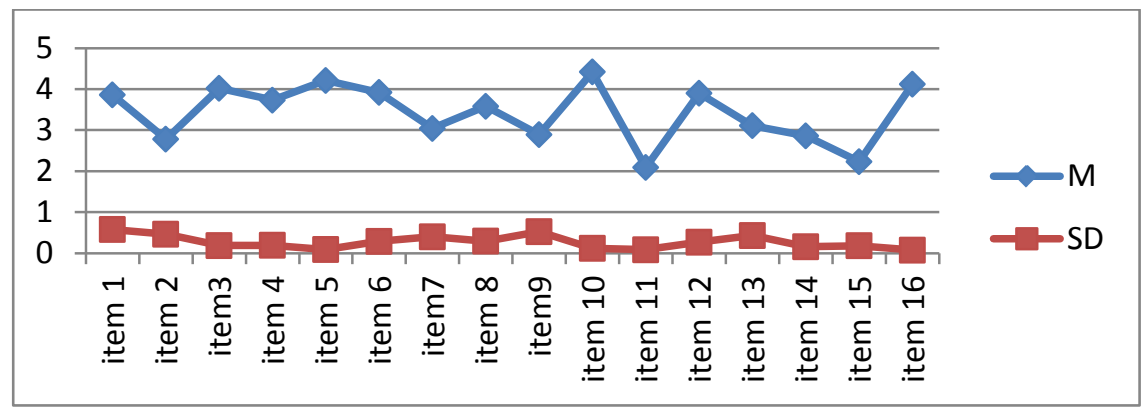

Figure 1. Mean $(\mathrm{M})$ and $\sigma(\mathrm{SD})$ values of the 16 items included in the questionnaire. 
Items 6 and 7 serve to clarify things in terms of the role of cognitive activity and cognitive interest in integrated ESP and/or CLIL courses.

The students' views about ESP and CLIL for English-improving purposes are checked in items 8 and 9. ESP programmes are designed for students who want to improve their English in a certain professional field of study, normally taught at university, whereas the CLIL approach is said to be successful and to help to improve students' foreign language competence, even in bilingual contexts where English has little social presence (Lasagabaster 2008).

Items 10 and 11 provide information to know to what extent ESP and/or CLIL have helped them to learn content in English. Content-based instruction comprises the steps of vocabulary acquisition, oral and written summarizing, making oral presentations, and participating in project preparation and delivery. All these stages employ learners' professional knowledge and prompt them to activate it in a foreign language. Being content-related, the areas of language learning described above allow learners to develop competence through a sequence of thematically organized tasks. This is a common procedure in traditional ESP courses, where the use of language is restricted to a set of social and thematic areas chiefly for the unambiguous transfer of (technical) information (Gramley 2008), but it cannot be denied that in CLIL courses the approach and aim are very similar.

In items 12 and 13, information is gathered about how much the students think their English has improved due to their ESP and/or CLIL teachers. The results show an important and surprising difference between the two. The theory behind CLIL is that complementary subjects taught at the same time result in improved internalization and retention. Essentially, CLIL enables you to take advantage of the connections between language and specific subject-related content in order to improve the educational efficiency. In many cases, CLIL can increase your students' motivation to learn what you are teaching them. This can enable them to progress more quickly and solidly than they would with deliberately separated subjects. For this to happen, all we have to do, according to CLIL supporters, is to make sure that the content-specific subject is the primary objective and that the linguistic goals are secondary, as this would provide consistency and sturdy scaffolding on which to build linguistic progress. The students 
were asked about this linguistic progress and, according to the results obtained, it seems to be significantly higher through ESP lessons. CLIL is not a panacea (yet), but ESP is no panacea either. Nobody should expect near-native levels of proficiency, but improvement can be expected with both approaches.

Items 14 and 15 include crucial information with respect to the future of ESP and CLIL. The students are not sure if ESP lessons are necessary when in the presence of CLIL lessons and they are very consistent in their answers (low level of dispersion). However, their opinion about whether CLIL lessons are necessary is much clearer, since they consider that they are (again, with a low level of dispersion).

Finally, item 16 is one of the fundamental items in the questionnaire, since their perception on this topic may influence future actions implemented by teaching authorities. Surprisingly, the students are very much in favour of the compatibility of ESP and CLIL lessons.

The mean and $\sigma$ values (4.23 and 0.057) for the statement within the last block of the questionnaire, "I would have provided the same answers in this questionnaire if the interviewer had been a CLIL teacher”, provides the overall results of the questionnaire with potential validity.

\section{DISCUSSION AND CONCLUSION}

Language learning is not a simple linear process but a functional diversification, an extension of the learner's communicative range. In a language-in-context model, language development is viewed as a process of learning to control an increasing range of registers and genres, rather than viewing development in relative terms of 'more' or 'less' language. CLIL and ESP learners' success is largely related to the opportunities they have to participate in a range of authentic learning contexts and meaning-making, and the support (in terms of scaffolding techniques) that they are given to do so successfully in English (Hammond and Gibbons 2005).

ESP practitioners understand that authentic learning contexts are obvious when dealing with content courses (irrespective of the language used), but they also know that students need to know certain linguistic tools when English is used as a means of instruction. Some teachers involved in CLIL are not fully aware of this need. The 
following anecdote can illustrate this belief. One of my colleagues, who teaches Electronics courses, shared with me, in a friendly way, his thoughts on ESP and CLIL: "We teach engineering courses in English. The medium of instruction is English. The textbooks we use are in English... Then, what is the need for you (English language teachers) to teach English to the students?” My answer was: “We don't teach English as a subject. We teach the language as a life skill or survival skill. You explain certain technical concepts in English, whereas we teach students how to communicate effectively and how to develop their language skills. You want your students to make presentations, write reports, prepare proposals, etc. and we teach them these skills.”

What many people believe, CLIL practitioners included, is that in principle CLIL is applicable regardless of the context; hence, by introducing CLIL from an early age at school, students will not have to take any ESP courses in future.

The UBC is CLILing but no quantifiable feedback - in the broad sense - has been provided so far. No information has been made public with respect to the strong and/or weak points of the new approach. Despite the fact that wide recognition has been afforded to CLIL over the years (Baker 2001, Dalton-Puffer and Smit 2007, Genesee 1987), because providing curriculum content in a second or foreign language can lead to both increased subject knowledge and enhanced L2 proficiency, in the case of the UBC this assumption must be taken with some caution. This can be understood if we consider that CLIL approaches have tended to develop in primary and secondary schools in the BAC, where the content is at a lower level and is therefore more accessible for language teachers, but at tertiary level the linguistic complexity increases probably beyond the limits of average university content teaching staff. CLIL might then become no more than "a brilliant business idea” (Smith and Hayworth 2005: 70), allowing publishers to churn out new titles, all of which claim to be in line with CLIL theories.

The theoretical definitions of CLIL appear to be so wide as to admit any form of language teaching. Moreover, CLIL itself is not a well-established teaching practice (of course, with exceptions). In some instances where CLIL has been implemented there have been concerns about the decrease in the level of the subject matter due to the oversimplification of the language because of the differences in the learners' linguistic ability in the foreign language and, in the case of the UBC, because of the prospective 
differences in the teachers' linguistic ability in the foreign language. ESP, in contrast, is supported by a wide body of theory. Added to that, there are an increasing number of course books covering more and more specialized domains and ESP does this by offering definite content: content that is geared to the students' wants and needs.

As a matter of policy, one school or university may decide to practice 'immersion' but this does not mean that it is CLILing. The teacher may just treat the students as if they were native speakers and 'immerse' them in an academic context that attempts to simulate the type of educational conditions and experiences that a native-speaker pupil would expect to undergo. Yet the social context of the student will in most cases be an obvious drawback and will act as a friction force putting up resistance against the relative motion of a solid surface (language learning).

On the other hand, teachers who deliver their material in the L2 cannot assume that they are being understood. The implications are obvious: 1) Teachers would have to adjust their methodology to ensure that the students understand the content. 2) The adjustment would mean more task-based and therefore more learner-centred materials. And 3) The materials would focus more clearly on the role that language plays in the students' assimilation of the concepts in the subject matter.

It is difficult to accept that a teacher or learner is CLILing at present at the UBC. In exactly the same way, some ESP practices were criticized 30 years ago. Nevertheless, as Graddol (2006) states, there is a steady growth of CLIL in most European countries. He has warned that the need for specialist English teachers will decline rapidly - from university level downwards.

The need for language teachers should not change in terms of quantity, but today a different kind of language teacher is needed. Content belongs to content teachers but good teaching belongs to the good teacher. CLIL is being used, among other things, to 'unload' the students' timetable and, simultaneously, to find room for more EFL instruction. In our humble opinion, input is not enough - which means that CLIL is not enough without some kind of EFL support. EFL instruction must therefore supplement and enhance language input from CLIL instruction to develop language proficiency by getting the students to use the language for increasingly demanding tasks while providing them with feedback and support. 
Dafouz and Guerrini (2009) claimed that things will improve in the future, as a new generation of CLIL students and teachers reaches higher education. However, despite all the institutional efforts in favour of CLIL in the Basque Country, language teachers are facing a tough challenge and, probably, all we can talk about is a pre-CLIL period at the UBC. Nevertheless, inertia is being generated for CLIL while, with respect to ESP, a clear slow-down process can be observed. Despite this obvious fact, the main conclusion of our study is that CLIL and ESP courses seem to be compatible (at least at present) at the UBC. Nevertheless, this last statement must be considered with caution, since the study carried out in this paper is only exploratory due to its small-scale approach (only 23 participants from a single school). Moreover, it should be pointed out that in this case, despite the fact that in this school a relatively larger number of students take either CLIL courses or ESP courses, only 23 take both. Further large-scale studies would be necessary to fully understand the nature of this recent phenomenon. These studies might focus on why some students choose CLIL courses but not ESP courses and vice versa (if any!), when both are readily available.

In other words, the synergic phenomenon mentioned within the previous section seems to be due to certain facts founded on the following: 1) a very favourable attitude of the students towards English (the highest means and the lowest SDs in this block are for item 3: "I like being taught in English" and item 5 "English will be important for me when working as an engineer”); 2) the level of awareness of the students with respect to language acquisition vs. learning content (item 10 "I have learnt more language than content in my ESP lessons” also receives a high mean with a very low SD); and 3) the feeling of compatibility of both types of courses (item 16 "ESP lessons and CLIL lessons are compatible with each other" also presents a high mean with a very low SD). Finally, more food for thought is presented. With more than 2 million international students, international education is a lucrative market. Most students are shared among 5 western nations, namely the USA, the UK, France, Germany and Australia. Moreover, the ratios between international students (they usually spend years in that country) and local students abroad (they usually travel overseas for only a few weeks) are overwhelmingly high (Australia 23:1; USA 15:1; UK 9:1). The rates in some European countries are also outstandingly high. For example, of the 38,000 students enrolled at the University of Copenhagen, 15\% are international students (Jensen and Thøgersen 
2011). This means that international students in these countries are seen primarily as financial resources. Could this be one of the reasons for the UBC to support the new approach so vehemently?

\section{REFERENCES}

Ammon, U. 1996. “The European Union (EU - formerly European Community). Status change during the last fifty years”. In Fishman, J.A., A.W. Conrad and A. RubalLópez (Eds.) Post-Imperial English. Status Change in Former British and American Colonies, 1940-1990. Berlin: Mouton de Gruyter, 241-267

Baker, C. 2001. Foundations of Bilingual Education and Bilingualism. Clevedon: Multilingual Matters.

Bell, C. 2006. “Specialised vocabulary”. English Teaching Professional 42, 35-36.

Costa, F. and Coleman, J.A. 2010. "Integrating content and language in higher education in Italy: Ongoing research”. International CLIL Research Journal 1 (3), 19-29.

Cenoz, J. and Gorter, D. 2011. “A holistic approach to multilingual education: Introduction”. The Modern Language Journal 95 (3), 339-345.

Coleman, J.A. 2006. “English-medium teaching in European higher education”. Language Teaching 39, 1-14.

Cummins, J. 1979. “Cognitive/academic language proficiency, linguistic interdependence, the optimum age question and some other matters". Working Papers on Bilingualism 19, 121-129.

Dafouz, E. and Guerrini, M.C. (Eds.) 2009. CLIL across Educational Levels: Experiences from Primary, Secondary and Tertiary Contexts. Madrid/London: Santillana Educación / Richmond Publishing.

Dalton-Puffer, C. 2008. “Outcomes and processes in Content and Language Integrated Learning (CLIL): Current research from Europe”. In Delanoy, W. and L. Volkmann (Eds.) Future Perspectives for English Language Teaching. Heidelberg: Carl Winter, 139-157. 
Dalton-Puffer, C. and Smit, U. (Eds.) 2007. Empirical Perspectives on CLIL Classroom Discourse. Frankfurt am Main: Peter Lang.

Dudley-Evans, T. and St John, M.J. 1998. Developments in English for Specific Purposes: A Multi-disciplinary Approach. Cambridge: Cambridge University Press.

Elorza, I. and Muñoa, I. 2008. "Promoting the minority language through integrated plurilingual language planning: The case of the ikastolas”. Language, Culture \& Curriculum 21 (1), 85-101.

Fernández, D.J. 2009. “CLIL at the university level: Relating language teaching with and through content teaching”. Latin American Journal of Content \& Language Integrated Learning 2 (2), 10-26.

Fortanet-Gómez, I. and Räisänen, C. (Eds.) 2008. ESP in European Higher Education: Integrating Language and Content. Amsterdam: John Benjamins.

Gallardo del Puerto, F. 2007. "Is L3 phonological competence affected by the learner's level of bilingualism?” International Journal of Multilingualism 4 (1), 1-16.

García, O. 2009. Bilingual Education in the 21st Century: A Global Perspective. Malden, MA: Wiley-Blackwell.

Gardner, R.C. and Lambert, W.E. 1972. Attitudes and Motivation in Second Language Learning. Rowley, MA: Newbury House.

Genesee, F. 1987. Learning Through Two Languages. Cambridge, MA: Newbury House.

González Ardeo, J.M. 2003. “Attitude towards English and ESP acquisition as an L2 or L3 at university”. Ibérica 6, 109-133.

Graddol, D. 2006. English Next. Why Global English May Mean the End of 'English as a Foreign Language’. London: British Council.

Gramley, S. 2008. “English for Specific Purposes (ESP)”. In Gramley, S. and V. Gramley (Eds.) Bielefeld Introduction to Applied Linguistics: A Course Book. Bielefeld, Germany: Aisthesis Verlag, 183-196. 
Hamel, R.E. 2007. "The dominance of English in the international scientific periodical literature and the future of language use in science”. AILA Review 20, 53-71.

Hammond, J. and Gibbons, P. 2005. "Putting scaffolding to work: The contribution of scaffolding in articulating ESL education”. Prospect 20 (1), 6-30.

Hughes, R. 2008. "Internationalization of higher education and language policy: Questions of quality and equity”. Higher Education Management and Policy 20, $1-18$.

Hutchinson, T. and Waters, A. 1987. English for Specific Purposes: A Learningcentered Approach. Cambridge: Cambridge University Press.

Irizar, T. and Chiappy, A. 2008. “Operational level 4: A Cuban project”. Professional and Academic English 32, 12-17.

Järvinen, H.M. 2007. “Language in Content and Language Integrated Learning (CLIL)”. In Marsh, D. and D. Wolff (Eds.) Diverse Contexts-Converging Goals. CLIL in Europe. Frankfurt am Main: Peter Lang, 253-260.

Jensen, C. and Thøgersen, J. 2011. “Danish university lecturers' attitudes towards English as the medium of instruction”. Ibérica 22, 13-33.

Khoury, S.B. and Berilgen-Duzgun, S. 2008. “CLIL: Lessons from the learner”. In Jendli, A., C. Coombe and S. Troudi (Eds.) Best Practice in Language Teaching. Dubai, United Arab Emirates: TESOL Arabia, 25-34.

Lasagabaster, D. 2008. "Foreign language competence in content and language integrated courses”. The Open Applied Linguistics Journal 1, 31-42.

Lasagabaster, D. and Sierra, J.M. 2009. "Language attitudes in CLIL and traditional EFL classes”. International CLIL Research Journal 1 (2), 4-17.

Lasagabaster, D. and Sierra, J.M. 2010. "Immersion and CLIL in English: more differences than similarities”. ELT Journal 64 (4), 367-375.

Lasagabaster, D. and Ruiz de Zarobe, Y. (Eds.) 2010. CLIL in Spain: Implementation, Results and Teacher Training. Newcastle upon Tyne, UK: Cambridge Scholars Publishing. 
Lorenzo, F. 2007. “The sociolinguistics of CLIL: Language planning and language change in 21st century Europe”. Revista Española de Lingüística Aplicada, volume monográfico, 27-38.

Marsh, D. 2002. CLIL European Dimension: Actions, Trends and Foresight Potential. <ec.europa.eu/education/languages/pdf/doc491_en.pdf>

Mauranen, A. and Ranta, E. (Eds.) 2009. English as a Lingua Franca: Studies and Findings. Newcastle upon Tyne, UK: Cambridge Scholars Publishing.

Micic, S. 2005. "Reforms in English for medical academic purposes in Belgrade”. Professional and Academic English 27, 4-9.

Navés, T. and Victori, M. 2010. “CLIL in Catalonia: An overview of research studies”. In Ruiz de Zarobe, Y. and D. Lasagabaster (Eds.) CLIL in Spain: Implementation, Results and Teacher Training. Newcastle Upon Tyne, UK: Cambridge Scholars Publishing, 36-49.

Phillipson, R. 2006. "Figuring out the Englishization of Europe”. In Leung, C. and J. Jenkins (Eds.) Reconfiguring Europe. London: Equinox, 65-86.

Phillipson, R. 2009. “English in higher education: panacea or pandemic?” Angles on the English-speaking World 9, 29-57.

Ruiz de Zarobe, Y. 2007. “CLIL in a bilingual community: Similarities and differences with the learning of English as a Foreign Language”. In Smit, U. and C. DaltonPuffer (Eds.) VIEWZ: Vienna English Working Papers (Special Issue: Current Research on CLIL 2) 16 (3), 47-52.

Ruiz de Zarobe, Y. and Jiménez Catalán, R.M. 2009. CLIL in Spain: Content and Language Integrated Learning: Evidence from Research in Europe. Bristol: Multilingual Matters.

Smith, K. and Heyworth, F. 2005. “The ELT Journal debate: Common European Framework? We don't need bureaucrats to tell us what to teach!”. In Beaven, B. (Ed.) IATEFL 2005. Cardiff Conference Selections. Canterbury, England: IATEFL, 70-72.

Wächter, B. 2004. Higher Education in a Changing Environment. Bonn: Lemmens. 
Wächter, B. 2008. Internationalisation and the European Higher Education Area, report prepared for the 'official Bologna seminar' of the Flemish government, Ghent. < $\quad$ http://www.ond.vlaanderen.be/hogeronderwijs/bologna/BolognaSeminars/ documents/Ghent/Ghent May08 Bernd Waechter.pdf>

Wächter, B. and Maiworm, F. 2008. English-taught Programmes in European Higher Education. The Picture in 2007. Bonn: Lemmens.

Wilkinson, R. and Zegers, V. (Eds.) 2008. Realizing Content and Language Integration in Higher Education. Maastricht, Netherlands: Maastricht University.

Received: 29 October 2012

Accepted: 13 August 2013

Cite this article as:

González Ardeo, J.M. 2013. “(In)compatibility of CLIL and ESP courses at university”. Language Value 5 (1), 24-47. Jaume I University ePress: Castelló, Spain. http://www.erevistes.uji.es/languagevalue. DOI: http://dx.doi.org/10.6035/LanguageV.2013.5.3

ISSN 1989-7103

Articles are copyrighted by their respective authors

\section{APPENDIX}

\begin{tabular}{|l|l|l|}
\hline Age & \multicolumn{1}{|c}{} \\
\hline Gender & $\diamond$ Male & $\diamond$ Female \\
\hline
\end{tabular}

\begin{tabular}{|c|c|c|c|c|c|c|}
\hline \multicolumn{7}{|c|}{ 5: strongly agree; 4: agree; 3: neither agree nor disagree; 2: disagree; 1: strongly disagree } \\
\hline & ITEMS & 5 & 4 & 3 & 2 & 1 \\
\hline 1 & I like speaking/reading/writing in English & & & & & \\
\hline 2 & English should be taught to all pupils in the Basque Country & & & & & \\
\hline 3 & I like being taught in English & & & & & \\
\hline 4 & English is a language worth learning & & & & & \\
\hline 5 & English will be important for me when working as an engineer & & & & & \\
\hline 6 & ESP lessons have been interesting and useful & & & & & \\
\hline 7 & CLIL lessons have been interesting and useful & & & & & \\
\hline 8 & ESP lessons have helped me to improve my English considerably & & & & & \\
\hline 9 & CLIL lessons have helped me to improve my English considerably & & & & & \\
\hline 10 & I have learnt more language than content in my ESP lessons & & & & & \\
\hline 11 & I have learnt more language than content in my CLIL lessons & & & & & \\
\hline 12 & My ESP teachers have had a beneficial effect on my English & & & & & \\
\hline 13 & My CLIL teachers have had a beneficial effect on my English & & & & & \\
\hline 14 & ESP lessons are unnecessary if you attend CLIL lessons & & & & & \\
\hline 15 & CLIL lessons are unnecessary if you attend ESP lessons & & & & & \\
\hline 16 & ESP lessons and CLIL lessons are compatible with each other & & & & & \\
\hline & $\begin{array}{l}\text { I would have provided the same answers in this questionnaire if the interviewer } \\
\text { had been a CLIL teacher }\end{array}$ & & & & & \\
\hline
\end{tabular}

*ESP stands for English for Specific Purposes / CLIL stands for Content and Language Integrated Learning 